\title{
Resenha: As dimensões do ensino e da aprendizagem nos processos avaliativos da educação superior
}

\author{
Carla Cristine Tramontina \\ Universidade de Passo Fundo - Brasil
}

Pensar a avaliação no Ensino Superior é fundamental para o desenvolvimento de uma prática pedagógica crítica e reflexiva. Nessa perspectiva, fica o desafio aos educadores e gestores que atuam no Ensino Superior de pensarem e implantarem processos avaliativos que contribuam para a autoformação dos sujeitos, possibilitando que esses sejam capazes de analisar, interpretar, relacionar, compreender e refletir sobre o seu próprio processo formativo. Além disso, cabe ao educador diversificar os instrumentos avaliativos de suas práticas, construindo processos de forma contínua durante o percurso formativo dos acadêmicos e com o intuito de perceber os conhecimentos por eles internalizados e, também, como uma forma de autoavaliar o seu próprio trabalho.

Essa discussão vem sendo debatida há muito tempo no mundo acadêmico. É parte fundamental do processo de aprender a aprender, pois oferece respostas ao trabalho do educador e do processo formativo do acadêmico. Percebe-se que é um tema que não se esgota e que perpassa todas as etapas de ensino, sendo considerada imprescindível ser repensada e teorizada para atender as demandas que o mundo contemporâneo exige. Cabe destacar a preocupação de pesquisadores com relação ao tema em foco e o comprometimento dos mesmos em responder de forma eficiente aos desafios apresentados no decorrer dos tempos.

Nesse sentido, as investigações e discussões sobre essa temática protagonizam o Volume 04 da Coleção Avaliação do ensino superior: perspectivas de ensino e aprendizagem, 2018, Editora CRV, desenvolvido a partir das interações e contribuições do Grupo de Trabalho Universidades e Políticas Públicas de Educação do Conselho de Pró-Mobilidade Internacional (Clacso, 2016-2019), ao Programa de Pró-Mobilidade Internacional (Capes/AUPL), à Rede de Estudos e Pesquisas em Educação Superior (REPES) e ao Grupo de Estudos e Pesquisas sobre Educação Superior (GEPES/UPF). No presente livro, os autores compartilham investigações e experiências desenvolvidas em diversas Universidades do Brasil, México e da Colômbia.

A organização do volume é de competência dos professores Gionara Tauchen e Altair Alberto Fávero. Tauchen possui Pós-Doutorado em Ensino-aprendizagem na Universidade Eduardo Mondlane (UEM/Moçambique), Doutorado em Educação pela Pontifícia Universidade Católica do Rio Grande do Sul (PUC/RS), Mestrado em Educação pela Universidade de Santa Maria (UFSM), Graduada em Pedagogia pela UFSM, Professora adjunta da Universidade Federal de Rio Grande (FURG), Docente permanente dos Programas de Pós-Graduação em Educação e em Educação em Ciências: Química da Vida e Saúde na FURG. Fávero possui Pós-Doutorado (Bolsista Capes) pela Universidade 
Autónoma del Estado de México (UAEMéx), Doutorado em Educação pela Universidade Federal do Rio Grande do Sul (UFRGS), Mestre em Filosofia do Conhecimento pela Pontífica Universidade Católica do Rio Grande do Sul (PUC/RS), Especialista em Epistemologia das Ciências Sociais pela Universidade de Passo Fundo (UPF) e Graduado em Filosofia (UPF). Atua como professor e pesquisador no Curso de Filosofia, no Mestrado e Doutorado em Educação da Universidade de Passo Fundo e atualmente é coordenador do Programa de Pós-Graduação em Educação desta Universidade (UPF).

O livro está estruturado em 09 capítulos e objetiva contribuir para a discussão acerca dos impasses contemporâneos no processo da avaliação e da aprendizagem no Ensino Superior. Na obra, os autores procuram teorizar sobre concepções e temas relacionados à avaliação do ensino e da aprendizagem na Educação Superior com o intuito de contribuir para ampliar a compreensão do tema, possibilitando "o diálogo e a construção de possibilidades a partir da interação com diferentes contextos de investigação" (p. 14).

O primeiro capítulo, intitulado "O que avaliar? como avaliar? impasses contemporâneos no processo de avaliação no ensino superior" dos pesquisadores Humberto Calloni e Rodrigo Eder Zambam, busca refletir sobre as práticas, sentidos e significado da avaliação no Ensino Superior. Os autores procuram conceituar a avaliação partindo do genérico para o específico, retratando que no Ensino Superior busca-se preparar o estudante para o mercado de trabalho e o docente necessita ser coerente com o currículo e com a avaliação que será aplicada em sala de aula. Nesse sentido, busca-se uma avaliação que seja emancipatória, que provoque os sujeitos e supere a educação bancária. É tornar o aluno sujeito e protagonista do seu processo formativo, sendo pesquisador, problematizador e crítico do seu próprio processo de aprendizagem. Ao docente, cabe modificar a forma de avaliar. E a experiência dos autores que atuam no Ensino Superior comprovou isso: alunos mais participativos, desafiados a escrever, a pesquisar, a problematizar e a pensar. A escrita dos autores revela o processo realizado durante a prática e afirmam: "no nosso entendimento, o processo de retroação/retroalimentação formação/mercado pode estar exigindo um repensar sobre o que avaliar, como avaliar e por que avaliar" (p. 32).

O segundo capítulo tem como título A Avaliação Da Aprendizagem Na Educação Superior, dos autores Altair Alberto Fávero e Lidiane Limana Puiati Pagliarin. Fávero e Pagliarin discutem sobre os princípios e fundamentos da avaliação da aprendizagem no Ensino Superior. O SINAES e o ENADE são mecanismos para avaliar a qualidade do Ensino Superior, mas "percebe-se que ainda os resultados das avaliações vêm sendo utilizados mais como controle do que como processo para planejamento de ações futuras" (p. 37). É necessário que no Ensino Superior os professores revejam as formas de avaliar, "repensem os formatos avaliativos, os instrumentos, bem como o objetivo das avaliações da aprendizagem dos alunos desse nível de ensino" (p. 38) e, por consequência, "pode favorecer a qualidade de aprendizagem dos alunos" (p. 38). Dessa forma, o processo torna-se pedagógico, respeitando a especificidade e a cultura da universidade. 
No terceiro capítulo, "La evaluación del aprendizaje como desafio de los docentes", os autores Juan Manuel Castrejón Amezcua, Alondra Berenice Ruiz Virgen e Sara Aliria Jiménez Garcia discorrem sobre usos e finalidades do processo avaliativo no curso de graduação em Licenciatura em Engenharia Civil. O texto propõe uma configuração no processo de ensino aprendizagem no Ensino Superior e, através de pesquisas, buscou analisar a intervenção que as práticas avaliativas costumam exercer sobre o ponto de vista dos alunos em relação à aprendizagem. Por isso, os autores defendem que traçar objetivos estabelecendo metas durante o processo de ensino aprendizagem faz com que os protagonistas nesse processo sintam-se instigados a resolver as mais variadas situações que lhe forem apresentadas, tanto no âmbito laboral como no social.

O quarto capítulo do volume, intitulado "Metodologias ativas de ensino e aprendizagem e avaliação por matriz de competências na educação superior", escrito por Arnaldo Nogaro, propõe desenvolver nos acadêmicos habilidades para que possam aprender de forma contínua e ao longo de toda a vida acadêmica e profissional. O autor aborda as metodologias ativas (baseadas em resolução de problemas que desafiam o aluno a pensar e a encontrar saídas viáveis) e avaliação por matriz de competências (que permite conhecer a capacidade do aluno com relação ao conhecimento) no Ensino Superior. Para o autor, a "avaliação também deve mudar ou ser reorientada, assumindo caráter diagnóstico formativo" (p. 97).

O quinto capítulo tem como título "A lógica do mercado como critério de qualidade na avaliação da educação superior”, de Altair Alberto Fávero, Evandro Consaltér e Carina Tonieto. Os autores analisam as concepções de qualidade na avaliação da Educação Superior mediante a influência do discurso do mercado. Os dados apurados no capítulo permitem a constatação de que a avaliação também é uma maneira de legitimar o poder dos governos. A pesquisa realizada com dados do INEP (2017) deixou evidente "o caráter mercadológico que se oculta por trás de indicadores e chavões de excelência em IES" (p. 114). Essas instituições visam ao lucro e não procuram investir no desenvolvimento pessoal e profissional dos sujeitos. Embora apresentem bons resultados nos indicadores de avaliações direcionadas para o Ensino Superior, possuem pouco envolvimento com a pesquisa e a busca pelo conhecimento.

"Prácticas de evaluación inclusiva em la universidad", de autoria de Norma Guadalupe Márquez Cabellos, é o sexto capítulo do volume. O texto propõe uma reflexão acerca da Educação Inclusiva em universidades públicas e privadas mexicanas. Em um estudo qualitativo realizado na Universidade de Colima constatou-se que a educação inclusiva no contexto universitário deve garantir o acesso, a continuidade, a participação dinamizando e promovendo a diversidade, fomentando a aprendizagem. As práticas pedagógicas avaliativas devem nortear as ações educativas, reduzindo o impacto da limitação à aprendizagem.

Já o sétimo capítulo, intitulado "A pedagogia da alternância como dispositivo avaliativo/ formativo no contexto do ensino superior: pontos e contrapontos na educação do campo", tem a autoria de Sebastião Silva Soares e propõe pensar sobre a Pedagogia da Alternância no processo de ensinar e de aprender e na formação de professores na Educação do Campo. A Pedagogia da Alternância foi integrada no currículo das 
licenciaturas em Educação no Campo por meio do Edital de Seleção no 02/2012/SESU/SETEC/SECADI/MEC, de 31 de agosto de 2012. Com as narrativas dos professores formadores de instituições contempladas pelo referido edital, Silva procurou analisar os limites e as potencialidades da Pedagogia da Alternância quanto à avaliação e formação. A pesquisa revelou a necessidade dos professores "aprender a apreender os princípios da Pedagogia da Alternância como uma metodologia de avaliação/formação integrada ao mundo da vida" (p. 146). Além disso, buscar o diálogo entre saberes científicos e saberes populares visando a superar a transmissão de conhecimentos e ter como meta a aprendizagem dos alunos.

O oitavo capítulo, cujo título é "Avaliação do ensino superior no processo de afirmação da imagem positiva do ibero-ásio-afro-ameríndio: o cinema negro posto em questão", tem autoria de Celso Luiz Prudente. O estudo tenciona refletir sobre as relações étnico-raciais, o sentido democrático da avaliação, procurando incluir o conhecimento produzido pelos grupos subalternos. A reflexão com base no cinema negro possibilita a busca pela dimensão pedagógica, resgatando a identidade cultural dos sujeitos. Através desse texto, o autor destaca a "função da avaliação do ensino acadêmico, que se caracteriza como provimento de políticas públicas para democratização em favor do respeito à diversidade" (p. 166), tornando fundamental considerar e respeitar a imagem do outro, acolher o diferente e fazer a diferença com relação à avaliação, procurando incluir os sujeitos para que estes possam contribuir para a transformação social.

Por fim, o último capítulo da coletânea tem como título "Aprendizaje autorregulado y evaluación formativa em educación superior: reflexiones, critérios y retos em processos de retención y permanência estudiantil". É de autoria de Sergio Rodriguez Jerez, Rafael Alberto Méndez Romero, Jenniffer Lopera Moreno e Eliana Ortiz Castilla. O texto tem como foco principal a preocupação no que tange à criação de novas estratégias pedagógicas capazes de diminuir o abandono e a retenção no Ensino Superior. O grande desafio está em dissipar práticas educativas significativas, centradas na aprendizagem autorregulada - construto de estratégias de aprendizagem -, tendo seu protagonista o discente. Busca-se um enfoque constituído sumamente pela autorregulação da aprendizagem, o aprender a aprender, o desenvolvimento metacognitivo, fazendo com que se consolidem habilidades para o aprendiz envolver-se e persistir no processo de aprendizagem. Dessa forma, o processo de avaliação formativa com base nesses parâmetros se torna contínuo e interativo, tendo como meta a formação integral do estudante, envolvendo a compreensão de conteúdos tornando-os objetos de aprendizagem.

Uma análise geral do volume evidencia a densidade e qualidade da obra expressa por meio do seu referencial teórico, bem como pelo grupo de autores que apresentam em sua formação a pesquisa como alicerce. O livro é fruto de pesquisas e experiências de diversos países, o que qualifica ainda mais a obra, pois apresenta um panorama internacional sobre o tema. A formação acadêmica dos autores enriqueceu o trabalho, que através das suas pesquisas, ideias e perspectivas, deixaram a coletânea instigante para a leitura e reflexão em torno do tema da avaliação no Ensino Superior. Esta obra é de extrema importância para todos aqueles que buscam qualificar sua 
prática pedagógica junto aos seus educandos no que se refere à avaliação do Ensino Superior sob as perspectivas do ensino e da aprendizagem. A leitura dos capítulos que compõem o volume faz refletir, problematizar e repensar a avaliação no Ensino Superior, provocando o educador a rever seus instrumentos de avaliação, visando à concepção de sujeitos críticos, participativos e autônomos com relação à condução do seu processo formativo. Os textos têm como foco o Ensino Superior, mas os educadores das demais etapas de ensino também podem se sentir contemplados na leitura uma vez que é de fácil entendimento e apresenta elementos importantes em relação à avaliação.

\section{Referências}

Tauchen, G.; Fávero, A. A. (2018). Avaliação do Ensino Superior: perspectivas de ensino e aprendizagem. (Coleção Avaliação do Ensino Superior, volume 04). Curitiba: CRV.

\section{Biografia}

\section{Carla Cristine Tramontina}

Email: cctramontina@hotmail.com / ORCID: https://orcid.org/0000-0001-9423-3443 